\title{
Analysis of the Optimal Duration of Behavioral Observations Based on an Automated Continuous Monitoring System in Tree Swallows (Tachycineta bicolor): Is One Hour Good Enough?
}

\author{
Ádám Z. Lendvai ${ }^{1,2 a}{ }^{2}$, Çağlar Akçay ${ }^{1}$, Jenny Q. Ouyang ${ }^{1,3}$, Roslyn Dakin ${ }^{4,5}$, Alice \\ D. Domalik ${ }^{5}$, Prianka S. St John ${ }^{5}$, Mark Stanback ${ }^{6}$, Ignacio T. Moore ${ }^{1}$, Frances Bonier ${ }^{1,5}$ \\ 1 Department of Biological Sciences, Virginia Tech, Blacksburg, Virginia, United States of America, \\ 2 Department of Evolutionary Zoology and Human Biology, University of Debrecen, Debrecen, Hungary, \\ 3 The Netherlands Institute of Ecology (NIOO-KNAW), Wageningen, the Netherlands, 4 Department of \\ Zoology, University of British Columbia, Vancouver, BC, Canada, 5 Department of Biology, Queen's \\ University, Kingston, ON, Canada, 6 Department of Biology, Davidson College, North Carolina, United \\ States of America \\ a Current address: Department of Evolutionary Zoology and Human Biology, University of Debrecen, \\ Debrecen, Hungary
}

Citation: Lendvai ÁZ, Akçay Ç, Ouyang JQ, Dakin R, Domalik AD, St John PS, et al. (2015) Analysis of the Optimal Duration of Behavioral Observations Based on an Automated Continuous Monitoring System in Tree Swallows (Tachycineta bicolor): Is One Hour Good Enough? PLoS ONE 10(11): e0141194. doi:10.1371/journal.pone.0141194

Editor: Csaba Moskát, Hungarian Academy of Sciences, HUNGARY

Received: February 21, 2015

Accepted: October 20, 2015

Published: November 11, 2015

Copyright: @ 2015 Lendvai et al. This is an open access article distributed under the terms of the Creative Commons Attribution License, which permits unrestricted use, distribution, and reproduction in any medium, provided the original author and source are credited.

Data Availability Statement: All relevant data are within the paper and its Supporting Information files.

Funding: Funding was provided by a U.S. National Science Foundation (NSF) grant (FB, ITM, and MFH; IOS-1145625), the Natural Sciences and Engineering Research Council of Canada, and a Banting Postdoctoral Fellowship (FB). During the preparation of the manuscript, ÁZL was supported by a Hungarian Scientific Research Fund (OTKA K113108) and JQO by a NSF postdoctoral grant (DBI-1306025).

\section{Abstract}

Studies of animal behavior often rely on human observation, which introduces a number of limitations on sampling. Recent developments in automated logging of behaviors make it possible to circumvent some of these problems. Once verified for efficacy and accuracy, these automated systems can be used to determine optimal sampling regimes for behavioral studies. Here, we used a radio-frequency identification (RFID) system to quantify parental effort in a bi-parental songbird species: the tree swallow (Tachycineta bicolor). We found that the accuracy of the RFID monitoring system was similar to that of video-recorded behavioral observations for quantifying parental visits. Using RFID monitoring, we also quantified the optimum duration of sampling periods for male and female parental effort by looking at the relationship between nest visit rates estimated from sampling periods with different durations and the total visit numbers for the day. The optimum sampling duration (the shortest observation time that explained the most variation in total daily visits per unit time) was $1 \mathrm{~h}$ for both sexes. These results show that RFID and other automated technologies can be used to quantify behavior when human observation is constrained, and the information from these monitoring technologies can be useful for evaluating the efficacy of human observation methods.

\section{Introduction}

The behavior of animals is notoriously variable. Therefore, finding a sampling regime that can accurately quantify behavior is challenging [1]. Most studies measuring animal behavior rely 
Competing Interests: The authors have declared that no competing interests exist. on human observation and subsequent analysis ('coding'). However, regardless of whether the observer watches the animals directly or quantifies behavior from recorded video, the procedure requires considerable time and effort. Consequently, availability of human resources and/ or video recording equipment limits such studies of animal behavior. In addition, it may be desirable to limit disturbance of the animals, (e.g., to reduce impacts of the observer on behavior), further constraining human activity around the study subjects. Even if there were no limits or constraints on human observation, statistical power rises as an asymptotic function of sample size; thus, after a certain point, the value of each additional sample begins to decline. Therefore, it may be more efficient to stop data collection before the informational asymptote is reached, to maximize the return for observer effort [2]. For all these reasons, a careful consideration of sampling effort is warranted.

Although the duration of observation periods has important consequences for statistical power, and thus the required sample size and effort, often the duration of observation periods used in a given study seems arbitrary. For instance, many behavioral studies of parental behavior use 1 hour behavioral watches [3-5], or sometimes even shorter observation periods [610]. These studies do not explicitly justify or validate the duration of the chosen observation period; therefore, the degree to which these observational samples are representative of subjects' behavior on longer time-scales is often unknown. Although several studies have provided analyses of different sampling regimes [2,11-13], these results may be difficult to generalize across species because of potential differences in the nature of behavior. Furthermore, some of these studies have relied solely on direct observations, which are by definition limited by manpower and human attention (e.g., a human observer cannot reasonably watch focal individuals from dawn to dusk), and human presence may also alter the behavior being studied.

Here, we use continuous recordings of parental provisioning visits from two populations of tree swallows (Tachycineta bicolor) to investigate the effect of different behavioral observation sample durations on the accuracy of estimated provisioning rates. We used an automated monitoring system based on radiofrequency identification (RFID) technology [14] that recorded every visit of the parents to the nest box throughout the entire day. Our aims were to determine the effect of observation period duration and statistical accuracy of estimated visit rate, so we can aid other researchers in choosing a sampling regime for their particular study system, and to demonstrate the degree to which duration of sampling regime can influence accuracy. We first validated RFID readings with data from 1-hr behavioral observations. Next, we estimated the optimal duration of behavioral observations that would maximize the amount of betweennest variation in parental behavior explained, while minimizing the effort to collect such samples. In doing so, we also emphasize that the optimal observation period for other systems may differ depending on various factors which we discuss below. Nonetheless, our approach to estimating the relationship between sampling effort and proportion of variance explained could be used in other systems to determine the required sampling effort to obtain a desired degree of accuracy.

\section{Materials and Methods}

\section{Study populations}

We investigated nestling provisioning behavior in a bi-parental songbird, the tree swallow, in two populations: at the Queen's University Biological Station, Ontario, Canada (N44'34'2.02", W76 ${ }^{\circ} 9^{\prime} 26.036^{\prime \prime}, 121 \mathrm{~m}$ elevation) in 2014, and near Davidson College, Davidson, North Carolina, USA (N34 31' 32.34", W80 52'40", 240m elevation) in 2014 and 2015. All procedures followed guidelines for animal care outlined by Association for the Study of Animal Behaviour, and the Animal Behavior Society and the Canadian Council on Animal Care, and were 
approved by the Institutional Animal Care and Use Committee at Virginia Tech (\#12-020) and the Canadian Wildlife Service (\#10771). In both populations, birds breed in nest boxes $[15,16]$. In tree swallows, females feed their offspring at a higher rate than males on average [17], and male visit rates show higher among-individual variance than female visit rates (RD, JQO, AZL unpublished data).

\section{Bird tagging and data collection}

Both parents were captured in their nest box (females: day 10 of incubation, males: day 2 or 3 post hatching) and equipped with a PIT-tag (passive integrated transponder) that was incorporated into a plastic leg band (EM4102 tags from IB Technology, UK). These leg bands were red for females and blue for the males. A hexagonal or square antenna (diagonally about $6 \mathrm{~cm}$ ) was fixed around the entrance of the nest box, which was later (from day 3 to day 5 post hatching), connected to an RFID reader. The reader attempted to detect a signal for 0.3 seconds, then paused for 0.2 seconds to save battery life and then this cycle was repeated continuously. This way, the reader recorded every time a bird equipped with a PIT tag passed through the antenna and thus the nest box entrance. The reader recorded the unique tag number and the current date and time to the seconds in a log file. We used "Generation 2" readers, an upgrade of the model described in [18] provided by Cellular Tracking Technology, PA, USA. The readers were powered from a $12 \mathrm{~V}, 5 \mathrm{Ah}$ motorcycle battery $(8.9 \times 7.1 \times 10.1 \mathrm{~cm})$. The reader and the battery were placed in a waterproof plastic container and hidden in the grass, below the nest box. To save power, we programmed the readers to turn off during the night (between 22:00 and 04:00). Therefore, on day 5 , the readers recorded all visits that either parent made to the box during the entire day at $\mathrm{n}=18$ nests. In 46 cases, the readers were first set up on day 5 , typically in the morning, between 07:00 and 10:00, so the duration of daily recordings is shorter for these nests, but still covers most of the day (mean: $12.72 \pm 0.18$ (SE) hours at a site with approximately 15 hours of daylight). In an additional 10 nests, RFID readers were deployed in the same manner, but the RFID readers yielded fewer than 200 total reads for that day (male and female combined; compared to the rest of the nests, where the average number of total reads was $1281 \pm 149$ (SE)), which indicates that the tags or antennae at these nests were not working properly, or that the parents fed their nestlings at an unusually low rate. These nests were excluded from our analyses. The final sample sizes for RFID analyses in 2014 were 34 (Canada) and 30 (US) nests. To test whether our conclusions can be generalized through a wider range of nestling ages, in 2015, we also collected RFID logs from 13 nests on day 3 post hatching and 28 nests day 8 post hatching (US only).

From the RFID logs, we determined the number of nest visits by filtering out continuous readings, generated when a bird is perching on the nest entrance (i.e., adjacent to the antenna). Our measure of visit rate based on the RFID logs may overestimate the actual number of feeding visits (e.g., birds sometimes go into the nest box, reappear at the entrance and then go back to the box before finally leaving the box-this event would be treated as two separate visits in our analyses). Such cases, however, were relatively infrequent (see Results).

In 2014, each nest was also directly monitored by a human observer for one hour to quantify the visit rates of the parents, and to determine whether RFID logs provide a similar estimate of visit rates by correlating the observational data with the visit rate calculated from the RFID logs. A total of 45 nests were directly observed while the RFID readers were in operation. The observer sat at about $30 \mathrm{~m}$ from the nest box at an angle that would allow him or her to determine the color of band (and therefore the sex) every time a bird entered. Because our primary interest in this study was accuracy in quantifying between-nest variation, we used only one day (day 5) of observation at a standard stage of chick rearing. 


\section{Statistical analyses}

Our analyses proceeded in two stages. In the first stage, we compared the visits inferred from the RFID logs with the visits noted during the observations for the same hour. In the second stage of our analyses, we used the RFID data to determine if different sampling durations could reliably estimate overall daily behavior. We first calculated the overall daily visit rate (number of visits divided by the duration of the total recording period) for both males and females in each nest from the RFID logs. We used the same logs and sampled $1 \mathrm{~h}$-long periods starting at different times of the day using all possible start times and calculated the sample visit rate again for both sexes. Then, separately for males and females, we used a linear regression to test how well visit rates calculated from the $1 \mathrm{~h}$ samples predict the total daily visit rates. Because our focus was on between-nest variation, we extracted the $\mathrm{R}^{2}$ from the linear model as a measure of the proportion of variance explained. We also obtained $95 \%$ confidence intervals for these estimates using nonparametric bootstrapping. Specifically, we calculated the $\mathrm{R}^{2}$ of the linear relationship between the hourly and the daily feeding rate using a random sample with replacement and 10000 replicates.

Next, we repeated the above process while varying the duration of the sampling window from $15 \mathrm{~min}$ to $4 \mathrm{~h}$ by 15 -min increments. We set the maximum at $4 \mathrm{~h}$ because, in most field conditions, longer direct observations are not feasible, and even with video recordings, sampling is constrained by battery. For every hour from 07:00 to 17:00, we calculated the $R^{2}$ based on different sampling window durations separately for the sexes.

We next sought to determine the optimal sampling duration. To do that, we first fit a series of curves to the $\mathrm{R}^{2}$ obtained at different observation periods. We fitted multiple curves because, while we expected the data would follow a saturation curve (i.e., very long observations will reach an asymptote in terms of proportion of between-individual variation explained), we did not have an a priori expectation that the data would fit one particular type of saturation curve over another. In practice, the fitted curves differed little in their shape (see Results). We fit three models that are often used to model such relationships, using the package 'drc' [19] in the $\mathrm{R}$ computing environment (version 3.2) [20]. First, we fitted a three-parameter Gompertz growth curve. The Gompertz curve converges towards an asymptote and the steepness of the curve changes with an inflection point in between the start and the asymptotic part of the curve. Next, we fitted a three parameter Michaelis-Menten model, a saturation curve that does not have an inflection point, and a three parameter asymptotic regression. We estimated the goodness of fit of each model using 'modelFit' in 'drc', where a significant value indicates a lack of fit, and used the second order Akaike Information Criterion to compare the fit of different models. Finally, we also fit a general additive model to the data using the 'gam' function in the 'gam' package that uses penalized regression splines. This method fits the model using a penalized likelihood maximization, in which the model likelihood is modified by the addition of a penalty for each smooth function, resulting in a balance between smoothness and goodness of fit. It does not assume that there is an inflection point or asymptote.

We then used two optimization algorithms to find the marginal value that gives the optimal sampling effort, defined as the one that maximizes the rate of return of statistical accuracy in $\mathrm{R}^{2}$ units per unit of sampling time. First, for the Gompertz fit, we took the local minimum of the second derivative of the fitted curve, which gives the inflection point of the first derivative where the concavity of the steepness of the curve changes towards the asymptotic decrease. For the other fits, the steepness of the curve monotonically decreases, and therefore there is no inflection point. In these cases we used the 'minimally important change' threshold that is often used in clinical trials to find a balance between specificity and sensitivity of a treatment (that also follows a hyperbolic saturation curve), and that has been recently shown to provide 

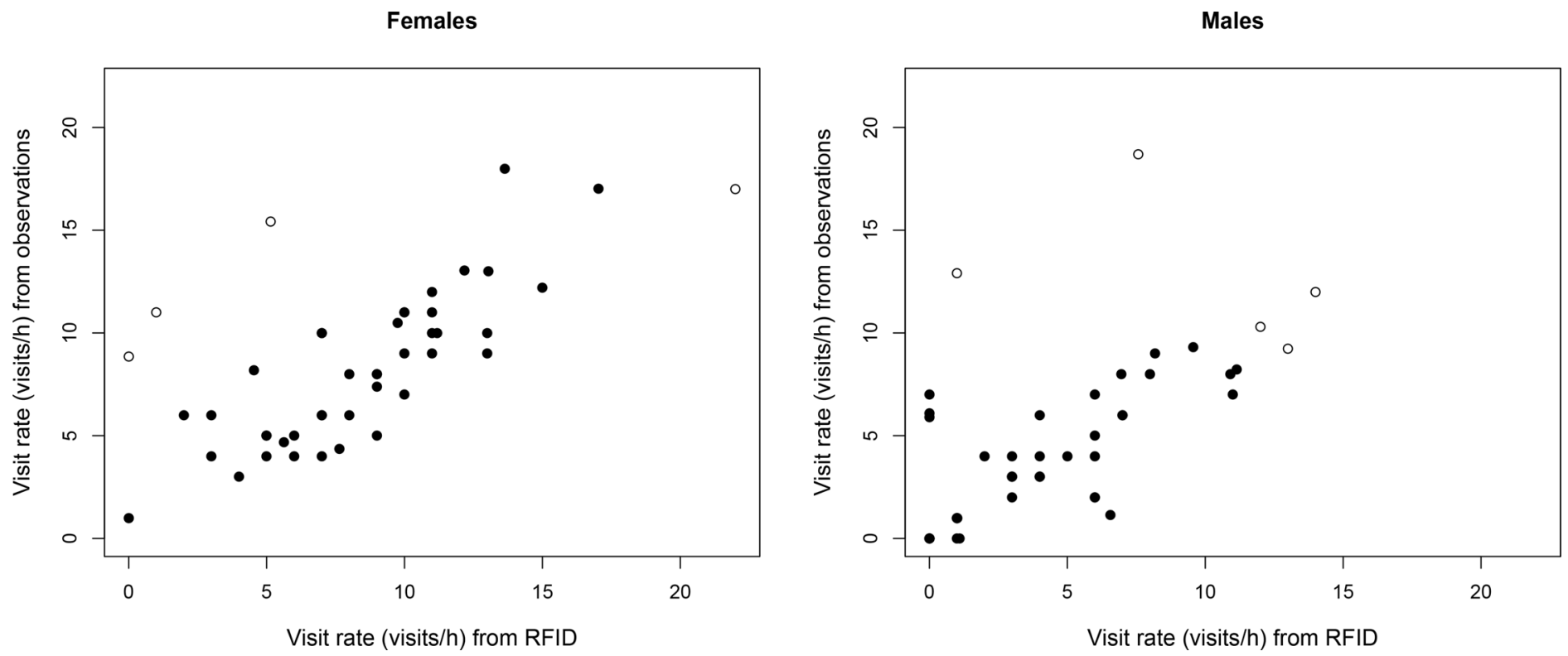

Fig 1. Visit rate (the number of feeding visits/h) of female and male tree swallows inferred from $1 \mathrm{~h}$-behavioral observations ( $y$-axis) and RFID readings (x-axis). Open circles denote influential data points that have disproportionate effect on the relationship as measured by the 'influence.measures' function in R. Note that the statistical analyses provided in the main text were carried out including these data points, and therefore provide a conservative estimate of these relationships.

doi:10.1371/journal.pone.0141194.g001

the optimal cutoff value [21]. This method uses a sum of squares method to find the point on the curve that maximizes the outcome while minimizing the cost (in our case, statistical accuracy and observational duration, respectively). An R script of the analyses (S1 File) and the dataset (S2 File) are provided as electronic supporting information.

\section{Results}

Visit rates calculated from day 5 RFID logs and direct behavioral observations were highly correlated (females: $\mathrm{r}=0.68, \mathrm{p}=0.2 \times 10^{-7}$ and males: $\mathrm{r}=0.67, \mathrm{p}=0.4 \times 10^{-7} ; \mathrm{N}=43$, Fig 1 ). There was a strong positive linear relationship between visits inferred from RFID logs and directly observed visits, with only a few exceptions (Fig 1). In most cases, the exceptions involved the failure of the RFID system to detect visits that were noted by an observer, which may have been due to failure of the PIT-tag or the antenna, although observer error is also possible.

Next, we looked at the RFID logs of the entire day. In most nests, the cumulative number of visits increased monotonically and linearly during the day in both sexes (Fig 2), suggesting that diel variation in visit rate was negligible.

After combining data from both populations, we examined how the time of day when the $1 \mathrm{~h}$ sample began predicted the total daily visit rate. Observations of $1 \mathrm{~h}$ in duration significantly predicted the total daily visit rate across all start times (Table 1). However, the proportion of variance explained depended on when the $1 \mathrm{~h}$ sampling began. Mid-day sampling tended to provide the best estimates, whereas evening and early morning hours gave the worst estimates for both females and males.

All of the parametric models we tested showed good fit to the data with the monotonic Michaelis-Menten model giving the best fit for both sexes (females: $\mathrm{F}=0.078, \mathrm{p}=1.0$, males: $\mathrm{F}=0.036, \mathrm{p}=1.0)$. The Gompertz and the asymptotic regression (AR) models showed similar fit, but were somewhat less supported for the female dataset $(\triangle \mathrm{AICc}=3.763$ and 1.90 for 
(A)

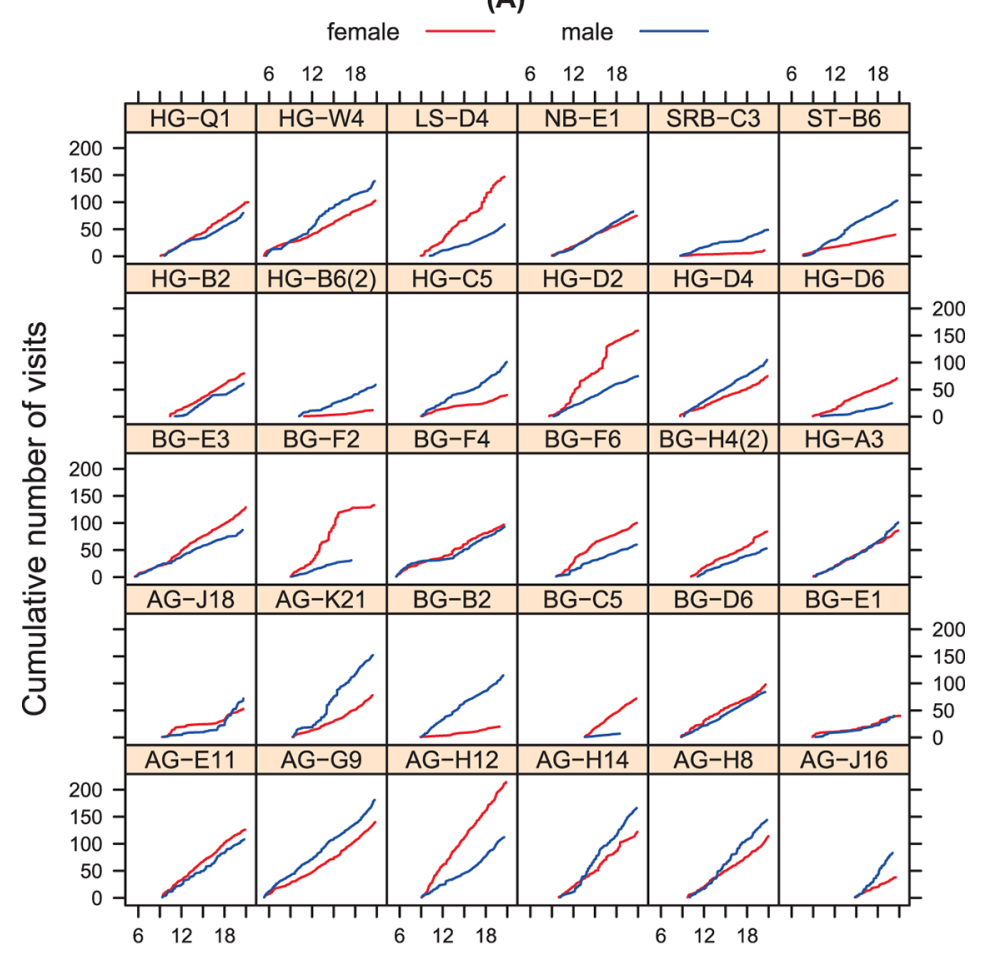

(B)

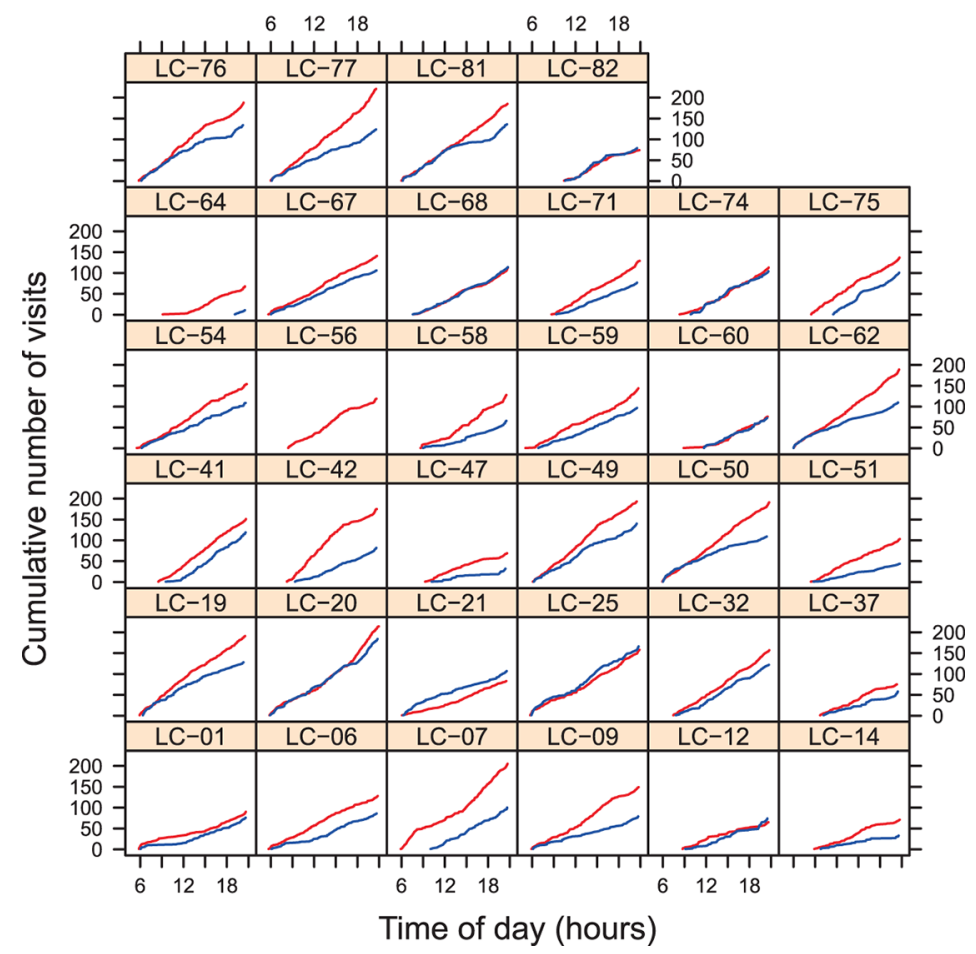

Fig 2. The cumulative number of parental visits in tree swallow nests in (A) Canada and (B) NorthCarolina. In both $(A)$ and $(B)$, each panel corresponds to one nest (the nest identifier is printed above each panel), with the blue line representing the male and the red line the female parent.

doi:10.1371/journal.pone.0141194.g002 
Table 1. Proportion of variance explained $\left(R^{2}\right)$ and its $95 \%$ confidence interval generated by bootstrapping, statistical significance (p-values), and the sample size $(\mathrm{N})$ of the relationship between $1 \mathrm{~h}$-samples and the total daily visit rate based on the time of onset of the $1 \mathrm{~h}$-sample for female and male tree swallows.

\begin{tabular}{|c|c|c|c|c|c|}
\hline time & $\mathrm{R}^{2}[95 \% \mathrm{Cl}]$ (female) & p-value (female) & $\mathbf{R}^{2}[95 \% \mathrm{Cl}]$ (male) & p-value (male) & $\mathbf{N}$ \\
\hline 06:00 & $0.60[0.31 ; 0.83]$ & $4.3 e-04$ & $0.34[0.08 ; 0.68]$ & $1.9 e-02$ & 16 \\
\hline 07:00 & $0.57[0.41 ; 0.77]$ & $3.2 e-04$ & $0.26[0.05 ; 0.57]$ & $3.0 \mathrm{e}-02$ & 18 \\
\hline 08:00 & $0.40[0.15 ; 0.77]$ & $2.0 e-03$ & $0.24[0.04 ; 0.54]$ & $2.5 e-02$ & 21 \\
\hline 09:00 & $0.40[0.19 ; 0.60]$ & $9.2 \mathrm{e}-06$ & $0.36[0.18 ; 0.57]$ & $3.5 e-05$ & 41 \\
\hline $10: 00$ & $0.52[0.31 ; 0.70]$ & $4.8 e-10$ & $0.25[0.09 ; 0.43]$ & $1.2 e-04$ & 55 \\
\hline $11: 00$ & $0.59[0.42 ; 0.74]$ & $2.9 e-13$ & $0.16[0.03 ; 0.41]$ & $1.1 \mathrm{e}-03$ & 62 \\
\hline $12: 00$ & $0.66[0.52 ; 0.78]$ & $1.6 e-15$ & $0.52[0.33 ; 0.71]$ & $4.0 e-11$ & 62 \\
\hline 13:00 & $0.70[0.55 ; 0.81]$ & $2.0 e-16$ & $0.65[0.46 ; 0.78]$ & $2.2 e-15$ & 62 \\
\hline $14: 00$ & $0.53[0.35 ; 0.71]$ & $1.8 e-11$ & $0.47[0.28 ; 0.63]$ & $5.6 e-10$ & 63 \\
\hline $15: 00$ & $0.50[0.31 ; 0.68]$ & $6.0 e-11$ & $0.64[0.46 ; 0.77]$ & $2.7 e-15$ & 64 \\
\hline $16: 00$ & $0.31[0.20 ; 0.59]$ & $1.6 e-06$ & $0.30[0.13 ; 0.48]$ & $3.0 e-06$ & 64 \\
\hline $17: 00$ & $0.49[0.31 ; 0.66]$ & $1.4 \mathrm{e}-10$ & $0.50[0.28 ; 0.68]$ & $8.4 \mathrm{e}-11$ & 64 \\
\hline $18: 00$ & $0.44[0.25 ; 0.61]$ & $3.1 e-09$ & $0.59[0.35 ; 0.81]$ & $8.9 e-14$ & 64 \\
\hline 19:00 & $0.50[0.30 ; 0.66]$ & $8.7 e-11$ & $0.47[0.27 ; 0.64]$ & $3.9 e-10$ & 64 \\
\hline
\end{tabular}

doi:10.1371/journal.pone.0141194.t001

Gompertz and AR respectively), whereas for the male dataset the difference was even smaller $(\triangle \mathrm{AICc}=0.860$ and 1.116 , respectively $)$, therefore these alternative models explained the relationship between duration of observation and $\mathrm{R}^{2}$ equally well (Fig 3 ). The general additive model (GAM) provided a monotonic smooth curve for both males and females, but these models had the least support (females: $\triangle \mathrm{AICc}=7.05$, males: $\triangle \mathrm{AICc}=3.33$ ).

Despite these differences in model fit, the Euclidean optimization function provided the same optimal duration for observations for all 4 curves, with an estimate of $1 \mathrm{~h}$ for both sexes (Fig 3). The concavity approach based on the Gompertz curve provided optimal duration estimates of 45 minutes for females and 1.5 hours for males.

Repeating the same analyses on day 3 and day 8 logs on a different set of individuals from 2015 gave identical results. The optimal duration of sampling (calculated using the Euclidean optimization) was $1 \mathrm{~h}$ for both males and females provisioning younger (day 3 ) and older (day 8 ) nestlings. Similarly to the day 5 records, the concavity approach provided estimates of 45 minutes for females and 1.5 hours for males as an optimal duration for both day 3 and day 8 nestling ages.

\section{Discussion}

In this study, we demonstrated the utility of RFID data loggers for quantifying nest visit rates in a small songbird, and quantified the relationship between sampling period duration and statistical accuracy of estimates of parental behavior. We provide an optimization method that can be easily applied to provisioning data from other systems, whether collected by behavioral observations or by an automated recording system. Our results therefore provide a template for other behavioral studies seeking to measure behavioral traits with accuracy while maximizing efficiency.

For chick-rearing tree swallows, the optimal sampling period duration of about $1 \mathrm{~h}$ for both sexes was robust to different curved fits to the data. A different optimization algorithm based on the change of the steepness of the curve provided a slightly different estimate: $45 \mathrm{~min}$ for females and $1.5 \mathrm{~h}$ for males. Note that the latter approach only works with the Gompertz growth function with an inflection point. The Gompertz function did not fit our data as well as 


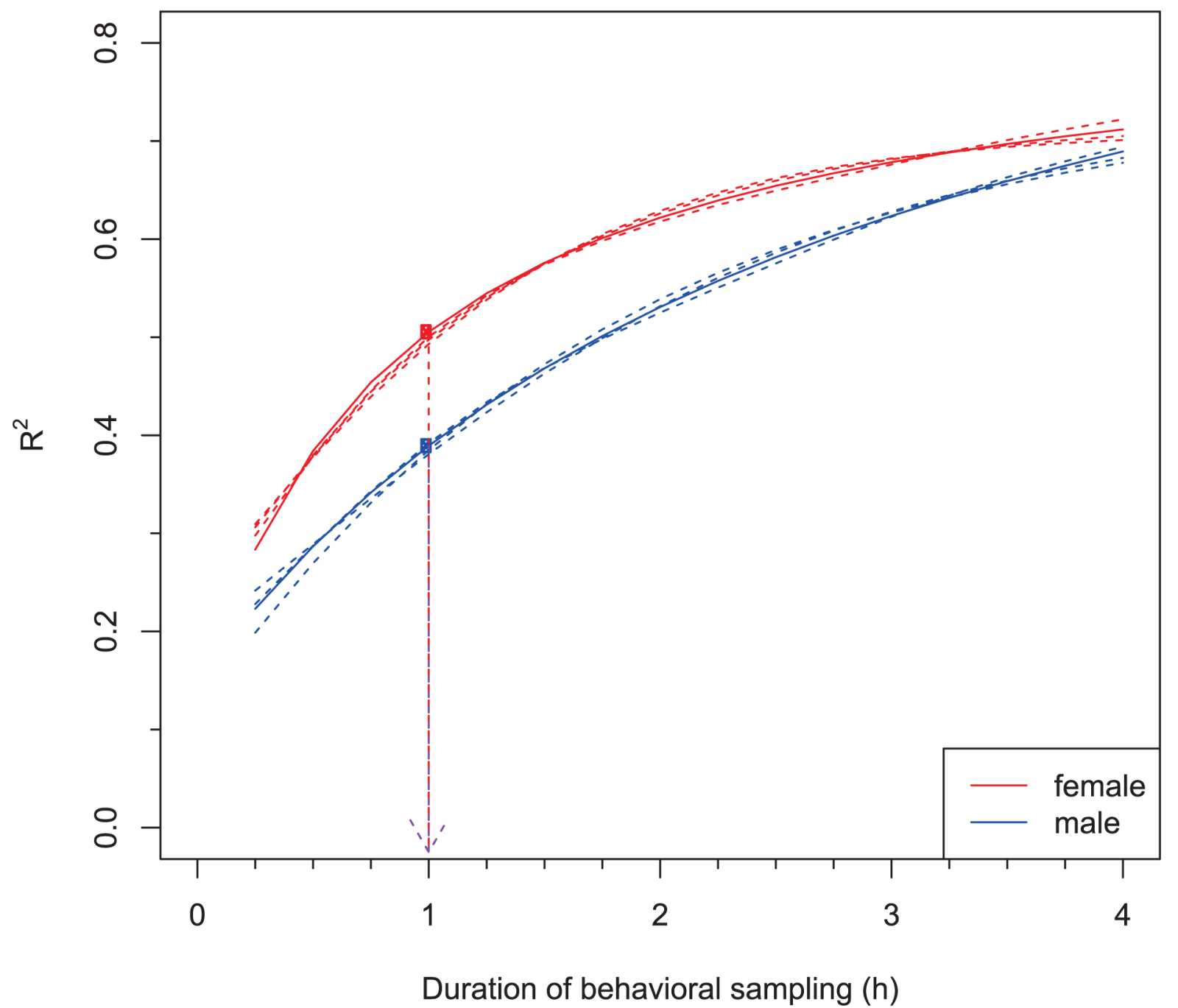

Fig 3. Optimal durations of observation periods for female and male tree swallows. The solid lines show the best fit curve to the data (a three parameter Michaelis-Menten model) for the relation between $\mathrm{R}^{2}$ and observation period duration ( 15 minutes -4 hours). The dashed lines show three alternative model fits (Gompertz, Asymptotic regression and General Additive Model). Red and blue dots indicate the optimal sampling effort for females and males respectively, that maximizes $\mathrm{R}^{2}$ and minimizes the duration of observation (indicated by the dashed arrows).

doi:10.1371/journal.pone.0141194.g003 
Table 2. Summary of published results testing different sampling regimes.

\begin{tabular}{|c|c|c|c|c|}
\hline Species & $\begin{array}{l}\text { Data collection } \\
\text { method }\end{array}$ & $\begin{array}{l}\text { Sampling } \\
\text { durations }\end{array}$ & Is $1 \mathrm{~h}$ good enough? ${ }^{\mathrm{a}}$ & Reference \\
\hline $\begin{array}{l}\text { Eastern kingbird (Tyrannus } \\
\text { tyrannus) }\end{array}$ & observations & $1 \mathrm{~h}$ vs $2-3 \mathrm{~h}$ & yes & [13] \\
\hline $\begin{array}{l}\text { Savannah sparrow (Passerculus } \\
\text { sandwichensis) }\end{array}$ & observations & $2 \mathrm{~h}$ vs whole day & $\begin{array}{l}1 \mathrm{~h} \text { was not tested, but } 2 \mathrm{~h} \text { samples gave estimates that } \\
\text { agreed closely with the longer observations }\end{array}$ & [25] \\
\hline Blue tit (Cyanistes caeruleus) & RFID & $\begin{array}{l}\text { 1h or } 2 \mathrm{~h} \text { vs whole } \\
\text { day }\end{array}$ & yes & [26] \\
\hline Blue tit (Cyanistes caeruleus) & RFID & 1h vs whole day & yes & [11] \\
\hline $\begin{array}{l}\text { House sparrow (Passer } \\
\text { domesticus) }\end{array}$ & observations & $\begin{array}{l}\text { 1h or } 2 \mathrm{~h} \text { vs whole } \\
\text { day }\end{array}$ & $\begin{array}{l}\text { yes, but } 2 \times 1 \mathrm{~h} \text { or } 2 \mathrm{~h} \text { observations yielded more accurate } \\
\text { estimates }\end{array}$ & [2] \\
\hline Great tit (Parus major) & $\begin{array}{l}\text { infrared } \\
\text { microcamera }\end{array}$ & $\begin{array}{l}\text { 1h vs } 7 \mathrm{~h}(7: 00- \\
14: 00)\end{array}$ & yes & [12] \\
\hline $\begin{array}{l}\text { Tree swallow (Tachycineta } \\
\text { bicolor) }\end{array}$ & RFID & $\begin{array}{l}15 \text { min- } 4 \mathrm{~h} \text { vs } \\
\text { whole day }\end{array}$ & yes & this study \\
\hline
\end{tabular}

a This column indicates whether $1 \mathrm{~h}$ sample could significantly predict longer (or whole day) provisioning behavior.

doi:10.1371/journal.pone.0141194.t002

variation in feeding rates among individuals (Table 2). These studies, however, typically tested only $1 \mathrm{~h}$ or $2 \mathrm{~h}$ as a sampling period. Here, we tested 16 different sample durations (from 15 mins to $4 \mathrm{~h}$ ) across the entire day. We found that $1 \mathrm{~h}$ was in fact the optimal sampling time, given that it maximized accuracy while minimizing total sampling effort.

Interestingly, we did not observe a systematic effect of time of the day on accuracy $\left(R^{2}\right)$, although early morning and evening samples tended to give poorer estimates. Indeed, the cumulative number of observations increases steadily throughout the day in a linear fashion, which is consistent with earlier observations that tree swallows feed their young during daylight hours at a relatively constant rate $[27,28]$. Studies of avian parental care usually concentrate on the morning hours, mainly because the activity of insectivorous birds is often the highest during the early hours of the day and one might think that a relatively short observation period is the most reliable when there are a lot of behavioral activities to record. However, our results corroborate earlier conclusions that this is not necessarily the case [11]. For example, in the blue tit (Cyanistes caeruleus), parental feeding rate is indeed the highest in early morning. However, the sex differences in blue tit feeding rates are also greater during the early hours, therefore, sampling these birds only during these hours could provide an inflated and the least reliable estimate of variation in sex differences in parental care patterns of this species [11].

We emphasize, however, that our approach here has been purely pragmatic, and increasing observation period duration to be greater than $1 \mathrm{~h}$ will always yield greater accuracy. If sample size is low, this may be desirable to attain greater statistical power. In our dataset, an increase of observation period duration from $1 \mathrm{~h}$ to $2 \mathrm{~h}$ could explain an additional $\sim 15 \%$ of the variance (Fig 3). So, as always in optimization, the currency will determine the optimal approach. We believe that being able to quantify the gains of increased sampling periods, as we do here, will be valuable to researchers trying to find the optimum sampling regime for their own system. But researchers also need to consider minimum level of variation explained that would be acceptable for their study, as well as other, e.g., logistical, constraints.

Finally, our data validate the use of RFID technology as a powerful tool to estimate parental visit rates. This tool provides an effective method for behavioral ecologists to circumvent the logistical and human resource limitations and observation bias that researchers face when designing behavioral field studies [29]. It is important to note that the RFID readers cannot discriminate between different behaviors performed during visits (such as feeding, brooding, nest 
defense, or courtship/copulation), and as such these methods are not yet able to completely replace behavioral observations for a variety of scientific questions (e.g. when researchers are interested in classifying types of social interactions). That said, the benefits of all-day monitoring might outweigh the limitations of such a system, for some scientific questions, such as those that require quantification of feeding rates in nestbox breeding birds. Furthermore, the results presented here will be useful to those researchers using only behavioral observations as well. We believe the combination of behavioral observations with RFID (or similar) monitoring technologies is the most fruitful strategy for field research in the immediate future.

\section{Supporting Information}

\section{S1 File. R script of the analysis.}

(R)

S2 File. Parental feeding rates by $\mathbf{1 5}$ minutes intervals provided as an $\mathrm{R}$ dataset. (RDATA)

\section{Acknowledgments}

We thank Djilali Hamza (Queen's University, Kingston) for his kind and generous help with fine-tuning the optimal inductance of our antennas. Thanks go to Eli Bridge, Jim Adelman, and Sahnzi Moyers for help with troubleshooting, László Pap for assembling reader units and Spencer and Drew Gill for help with the field work. We thank Zoltán Barta, András Kosztolányi and Mark F Haussmann for useful insights and discussion about the optimization algorithms. We are grateful to Frank Phelan and the Queen's University Biological Station for logistical help in the field and Mary Preston for continuous support for the field vehicle. We thank C. Morgan and Gosling Brothers for providing high-quality lubricant and B. Kulin for critical help and orientation in the dark.

\section{Author Contributions}

Conceived and designed the experiments: AZL JQO CA. Performed the experiments: AZL CA JQO MS AD PSJ. Analyzed the data: AZL CA RD. Contributed reagents/materials/analysis tools: ITM FB MS. Wrote the paper: AZL CA JQO RD FB ITM.

\section{References}

1. Haccou P, Meelis E. Statistical Analysis of Behavioural Data: An Approach Based on Time-structured Models. Oxford University Press; 1992.

2. Schwagmeyer $P$, Mock DW. How to minimize sample sizes while preserving statistical power. Anim Behav. 1997; 54: 470-474. PMID: 9268481

3. Ouyang JQ, Muturi M, Quetting M, Hau M. Small increases in corticosterone before the breeding season increase parental investment but not fitness in a wild passerine bird. Horm Behav. 2013; doi: 10. 1016/j.yhbeh.2013.03.002 PMID: 23523741

4. DeVries MS, Jawor JM. Natural variation in circulating testosterone does not predict nestling provisioning rates in the northern cardinal, Cardinalis cardinalis. Anim Behav. 2013; 85: 957-965. doi: 10.1016/j. anbehav.2013.02.019

5. Niederhauser JM, Bowman R. Testing sources of variation in nestling-stage nest success of Florida Scrub-Jays in suburban and wildland habitats. J Field Ornithol. 2014; 85: 180-195. doi: 10.1111/jofo. 12059

6. Carey M. Effects of Brood Size and Nestling Age on Parental Care by Male Field Sparrows (spizellaPusilla). Auk. 1990; 107: 580-586.

7. Verspoor JJ, Love OP, Rowland E, Chin EH, Williams TD. Sex-specific development of avian flight performance under experimentally altered rearing conditions. Behav Ecol. 2007; 18: 967-973. doi: 10. 1093/beheco/arm089 
8. Hogle NC, Burness G. Sex-specific environmental sensitivity is transient in nestling Tree Swallows (Tachycineta bicolor). J Ornithol. 2014; 155: 91-100. doi: 10.1007/s10336-013-0991-y

9. Bortolotti LE, Harriman VB, Clark RG, Dawson RD. Can changes in provisioning by parent birds account for seasonally declining patterns of offspring recruitment? Can J Zool. 2011; 89: 921-928. doi: 10.1139/z11-068

10. Gómez J, Michelson Cl, Bradley DW, Norris DR, Berzins LL, Dawson RD, et al. Effects of geolocators on reproductive performance and annual return rates of a migratory songbird. J Ornithol. 2013; 155: 37-44. doi: 10.1007/s10336-013-0984-x

11. García-Navas V, Sanz JJ. Environmental and Within-Nest Factors Influencing Nestling-Feeding Patterns of Mediterranean Blue Tits (Cyanistes caeruleus). The Condor. 2012; 114: 612-621. doi: 10. 1525/cond.2012.110120

12. Pagani-Nunez E, Carlos Senar J. One hour of sampling is enough: Great Tit Parus major parents feed their nestlings consistently across time. Acta Ornithol. 2013; 48: 194-200. doi: 10.3161/ $000164513 \times 678847$

13. Murphy MT, Chutter CM, Redmond LJ. Quantification of avian parental behavior: what are the minimum necessary sample times? J Field Ornithol. 2015; 86: 41-50. doi: 10.1111/jofo.12087

14. Bonter DN, Bridge ES. Applications of radio frequency identification (RFID) in ornithological research: a review. J Field Ornithol. 2011; 82: 1-10. doi: 10.1111/j.1557-9263.2010.00302.x

15. Bonier F, Moore IT, Martin PR, Robertson RJ. The relationship between fitness and baseline glucocorticoids in a passerine bird. Gen Comp Endocrinol. 2009; 163: 208-213. doi: 10.1016/j.ygcen.2008.12. 013 PMID: 19135999

16. Shutler D, Hussell DJT, Norris DR, Winkler DW, Robertson RJ, Bonier F, et al. Spatiotemporal Patterns in Nest Box Occupancy by Tree Swallows Across North America. Avian Conserv Ecol. 2012; 7. doi: 10. 5751/ACE-00517-070103

17. Ardia DR. Site- and sex-level differences in adult feeding behaviour and its consequences to offspring quality in tree swallows (Tachycineta bicolor) following brood-size manipulation. Can J Zool. 2007; 85: 847-854. doi: 10.1139/Z07-070

18. Bridge ES, Bonter DN. A low-cost radio frequency identification device for ornithological research. J Field Ornithol. 2011; 82: 52-59. doi: 10.1111/j.1557-9263.2010.00307.x

19. Ritz C, Streibig JC. Bioassay analysis using R. J Stat Softw. 2005; 12: 1-22.

20. R Core Team. R: A language and environment for statistical computing. R Foundation for Statistical Computing, ISBN 3-900051-07-0. Available: http://www.R-project.org. 2014.

21. Froud R, Abel G. Using ROC Curves to Choose Minimally Important Change Thresholds when Sensitivity and Specificity Are Valued Equally: The Forgotten Lesson of Pythagoras. Theoretical Considerations and an Example Application of Change in Health Status. PLoS ONE. 2014; 9: e114468. doi: 10. 1371/journal.pone.0114468 PMID: 25474472

22. Leonard M, Horn A. Provisioning rules in tree swallows. Behav Ecol Sociobiol. 1996; 38: 341-347. doi: $10.1007 /$ s002650050250

23. Whittingham LA, Dunn PO, Clotfelter ED. Parental allocation of food to nestling tree swallows: the influence of nestling behaviour, sex and paternity. Anim Behav. 2003; 65: 1203-1210. doi: 10.1006/anbe. 2003.2178

24. McCarty JP. The Number of Visits to the Nest by Parents Is an Accurate Measure of Food Delivered to Nestlings in Tree Swallows. J Field Ornithol. 2002; 73: 9-14. doi: 10.2307/4131060

25. Wheelwright NT, Schultz CB, Hodum PJ. Polygyny and male parental care in Savannah sparrows: effects on female fitness. Behav Ecol Sociobiol. 1992; 31: 279-289. doi: 10.1007/BF00171683

26. Johnsen A, Delhey K, Schlicht E, Peters A, Kempenaers B. Male sexual attractiveness and parental effort in blue tits: a test of the differential allocation hypothesis. Anim Behav. 2005; 70: 877-888. doi: 10.1016/j.anbehav.2005.01.005

27. Rose AP. Temporal and Individual Variation in Offspring Provisioning by Tree Swallows: A New Method of Automated Nest Attendance Monitoring. PLoS ONE. 2009; 4: e4111. doi: 10.1371/journal.pone. 0004111 PMID: 19119316

28. Ardia DR. Geographic variation in the trade-off between nestling growth rate and body condition in the tree swallow. The Condor. 2006; 108: 601-611. doi: 10.1650/0010-5422(2006)108[601:GVITTB]2.0. $\mathrm{CO} ; 2$

29. Tuyttens FAM, de Graaf S, Heerkens JLT, Jacobs L, Nalon E, Ott S, et al. Observer bias in animal behaviour research: can we believe what we score, if we score what we believe? Anim Behav. 20; 90: 273-280. doi: 10.1016/j.anbehav.2014.02.007 